\title{
Review of the Management Theory and Method of Loan Limitation
}

\author{
Mu Zhang ${ }^{1, a}$, Meng Wang ${ }^{1,2,3, b}$ \\ ${ }^{1}$ School of Finance, Guizhou University of Finance and Economics, Guiyang Guizhou 550025, \\ China \\ ${ }^{2}$ Guizhou Institute for Urban Economics and Development, Guizhou University of Finance and \\ Economics, Guiyang Guizhou 550025, China \\ ${ }^{3}$ Guizhou Institution for Technology Innovation \& Entrepreneurship Investment, Guizhou University \\ of Finance and Economics, Guiyang Guizhou 550025, China \\ arim_007@163.com, ${ }^{\mathrm{b}}$ 1511211838@qq.com
}

\begin{abstract}
Keywords: Commercial Banks; Credit Business; Loan Limitation; Corporate Clients of Banks; Research Summary

Abstract. Reasonably determining and using the loan limitation granted by commercial banks to their corporate clients, it has important theory meaning and realistic meaning for commercial banks to strengthen risk prevention and for lenders and borrowers to improve operational performance. In this paper, we summarized the domestic and foreign research status of the loan limitation of commercial banks from three aspects, such as the influencing factors of the loan limitation of commercial banks, the determining method of the loan limitation of commercial banks, and the utilization efficiency of the loan limitation of commercial banks and so on. The aim of our study is to promote the application and development of the loan limitation management theory and method.
\end{abstract}

\section{Introduction}

Loan limitation is the commercial Banks in view of the company's customers to determine a specific lending; it depends on the customers' solvency, management level, financial status, and the bank's own credit demand. On the one hand, if the commercial Banks' determination is too loose, the commercial Banks will face a greater risk of default. On the other hand, if the loan limitation which is determined by commercial Banks is too harsh, leads to a certain customer churn, declining the market shares. In addition, after company clients getting the commercial bank loan limitation, the use of loan limitation will directly affect the operating performance of the company. Therefore, it is of great theoretical and practical significance to reasonably determine and use the commercial bank to give the loan limitation of the company's customers, strengthen the risk prevention and control of commercial banks, and improve the operating performance of both sides. At present, the domestic and foreign commercial bank loan limitation research mainly concentrates in the following three aspects: Firstly, the factors affecting the loan limitation of commercial banks. Secondly, the method of commercial bank loan limitation determination. Thirdly, the efficiency of commercial bank loan limitation. This article will summarize the research status of domestic and foreign commercial bank loan limitation from three aspects, which are the influencing factors, determination methods, and the efficiency of commercial bank loan limitation, factors influencing the credit of commercial banks, for determining the amount of credit of commercial banks, In order to promote the application and development of the loan limitation management theory and method.

\section{Factors Affecting the Loan Limitation of Commercial Banks}

\section{(1) Main Influencing Factors.}

The main factors that affect the loan limitation of commercial banks include the following two aspects, for example: risk reward, term of contract, commitment cost, mortgage condition, and so on ${ }^{[1-3]}$ (Dennis \& Nandy, 2000; Andre, Mathieu \& Zhang, 2001; Zambaldi, Aranha \& Lopes et al, 2011); on the other hand, loan limitation and enterprise scale, growth, stability, profitability, the industry, the 
relationship between banks and enterprises, ownership concentration, diversification, current assets, current liabilities, owner's equity, fixed assets net value have relationship with credit rating ${ }^{\text {[4-10] }}$ (Ariccia \& Marquez, 2004; Sumit, 2004; Chakraborty \& Hu, 2006; Sufi, 2009; Pessarossi, Godlewski \& Weill, 2012; Tong, 2012; Sheng Lisheng and Wang Heng, 2007). For example, Shen Lisheng and Wang Heng (2007) ${ }^{[10]}$ use credit risk limits as explanatory variables, and use credit rating, owner's equity, current assets, fixed assets net value, current liabilities, main business cost, initial inventory, ending receivables, ending inventory, initial receivables as explanatory variables, and the artificial neural network model is used to test the influence factors of bank credit risk.

\section{(2) Other Influencing Factors.}

Some domestic scholars have also analyzed the other factors, such as interest rate, the rate of return on the company and the default rate. For example, Liu Lvke and Zhang Dingsheng (2012) ${ }^{[11]}$ studied the sensitivity of different amounts of loans to interest rate changes, by using data from the Australian 1997 third quarter to the fourth quarter of 2010. The results showed that changes in policy rates for different amount of loans, the impact on small and medium amount of loans is obvious, but there is no significant effect on large loans; at the same time, compared to the small loan, the degree of influence of interest rate policy on secondary loan amount is larger. Hu Jinyan and Zhang Qiang (2016) ${ }^{[12]}$, using the panel data of 66 small loan companies in Shandong province in 2013-2015, empirically tested the relationship between the average loan amount and the rate of return and the default rate. The results show that the average loan amount and income are inverted $U$ type relationship, the marginal revenue of the loan amount is affected by the default rate of the company, and showed a nonlinear threshold relationship.

\section{Method for Determining Loan Limitation of Commercial Banks}

\section{(1) Asset Liability Ratio Method.}

Li Jing (2003) ${ }^{[13]}$ think that the method of asset liability ratio is often used to determine the amount of credit by commercial banks. Although the asset liability ratio method considering corporate solvency, industry difference, various factors such as credit rating, and the operation is strong, but some scholars believe that, the asset liability ratio method pays too much attention to the asset liability ratio and net assets, which is lacking the ability to investigate its future cash flow. Therefore, Zhou Lanzhen (2003) ${ }^{[14]}$ think that, net cash flow as the basis for measuring the solvency of enterprises, is used to calculating the amount of loan limitations should be granted to commercial banks.

\section{(2) The Method for Determining Loan Limitation of Commercial Banks under Different} Information Conditions.

Considering whether the commercial bank and the company customer information is balanced or not, Leippoldy (2006) ${ }^{[15]}$ considered a continuous time model, which is based on the Game theory. It can be used to analyze the game relationship between credit providers and credit recipients under different information structure, and given the optimal loan limitation management strategy under different information systems. Zhou Jiangtao and Zhang Yan $(2007){ }^{[16]}$ give the method of determining the total credit amount under the condition of information equilibrium and the method of determining the total loan limitation under the condition of unbalanced information, the results of comparative analysis show that, due to the existence of unbalanced information, commercial banks will have their own information superiority over the stock of customers credit, resulting in credit concentration risk.

(3) The Method for Determining Loan Limitation of Commercial Banks based on Credit Grade.

Taking into account the nonlinear effects of the credit rating of the company's customers on the line of credit, Cheng Gong, Zhang Wei and Xiongxiong (2006) ${ }^{[17]}$ had come up with a reasonable basic assumption, the level of credit risk and credit rating of company have a corresponding relationship. According to this hypothesis, they proposed a method to determine the customer's risk level based on the customer credit rating, and constructed a nonlinear model of the bank customer risk limit. He Zili (2007) ${ }^{[18]}$ believes that the research on the quantitative model depends on the determination of the credit rating of the customer. From the new perspective of symbiosis theory, he examines the credit 
quota model, and puts forward the logic framework of the credit quota verification based on the symbiotic degree of the main parameters and characteristics of symbiotic degree analysis.

\section{(4) The Method for Determining Loan Limitation of Commercial Banks based on Economic Capital.}

In recent years, with the continuous changes of the international financial structure and the gradual intensification of financial risks, especially the frequent outbreak of various financial crises, the credit risk management system of commercial banks is becoming more and more prominent. For example, Taylor (2002) ${ }^{[19]}$ used the economic capital of commercial banks to measure the amount of personal loans in the loan amount, and thought the correlation between the loan applicant have an important impact on the determination of economic capital and loan limitations. On the basis of the introduction of economic capital, Zhou Kai (2008) ${ }^{[20]}$ optimized the allocation of risk and economic capital of the members of the group, so as to maximize the benefits on the basis of risk control. Liu Zhenhua and Xie Chi (2012) ${ }^{[21]}$ set up the loan limitation determination model from the maximum commercial bank's risk adjusted capital gains (RAROC), and carried on the empirical test.

\section{(5) Other Methods.}

In addition to the above methods, some scholars have studied the method of determining the credit line of commercial banks from other angles. According to the characteristics of the domestic financial market and bank credit risk management, Cheng Gong and Zhang Wei (2008) ${ }^{[22]}$ built a structured model of noise, and on this basis, they put forward a new method to calculate the customer's risk limit. Zhou Minghao and Wang Xiaoying (2010) ${ }^{[23]}$ introduced some problems existing in the current credit quota calculation, and put forward the methods to improve the credit loan amount.Assuming that the financial needs of customers at different times are subject to the Brown movement, Stanhouse, Schwarzkopf \& Ingram (2011) ${ }^{[24]}$ set up the credit line determination model of commercial banks from the perspective of the customer's financial needs. On the basis of flexible financial management theory, Miao Xilin (2014) ${ }^{[25]}$ adjusted the basis for the design of short-term loan amount calculation method by giving full play to people's subjective initiative and taking credit risk as a target. By investigating the provident fund deposit, the employees and their family members living standards, once the purchase and loan and credit status, Wang Yongfeng $(2015)^{[26]}$ summed up a set of all housing provident fund deposit fair and uniform, continuous and stable, flexible and simple calculation of the loan amount of mathematical methods.

\section{The Efficiency of Commercial Bank Loan Limitation}

Some domestic scholars have also studied the efficiency of commercial bank loan limitation. For example, Ren Shike, He Zhengwen and Xu Yu (2009) ${ }^{[27]}$ study the Max-NPV project scheduling problem based on the bank credit line, and discuss the influence of the bank credit line and customer payment proportion on the project income. Ying Qianwei and Luodanglun (2012) ${ }^{[28]}$ found that bank credit did have the ability to ease financing constraints and improve investment efficiency. However, the financing constraint is smaller, the quality of corporate governance is worse, in the strong relationship between government and enterprises, the efficiency of the use of credit lines (enhance the efficiency of investment) is lower. The results of this study to some extent, that the bank credit is to ease the role of financing constraints, but also in the high cost of agency enterprises may also lead to excessive investment and investment efficiency distortions. According to the financial data of A shares of listed companies in Shanghai and Shenzhen stock market form 2004 to 2014, Song Yibei (2016) ${ }^{[29]}$ made an empirical analysis of the relationship between government and enterprise, the amount of bank credit in the financing constraints and over investment. The study found that bank credit can alleviate the financing constraints, and reduce the investment cash flow sensitivity, but in the enterprises with strong relationship between government and enterprises, the investment cash flow sensitivity decline was not obvious, reflecting the "hedging effect of excessive investment to ease the financing constraints effect". In addition, based on the framework of structural model, considering the uniform 
credit line constraint, Chen Lin and Zhou Zongfang (2015) ${ }^{[30]}$ established the optimal allocation model of credit quota.

\section{Conclusions}

This paper has summarized the research status quo of the domestic and international loan limitations of commercial banks from three aspects, which are the influencing factors of the loan limitation of commercial banks, the method of determining the amount of loan limitation of commercial banks, and the efficiency of commercial banks. Among them, the empirical research of domestic and foreign scholars on the influence factors of the commercial bank loan limitation is more abundant, but the theoretical research is relatively weak. The domestic and foreign scholars have put forward the method of determining the credit amount of commercial banks from different angles, it mainly includes asset liability ratio method, the method of determining the credit amount of commercial banks under different information conditions, the method of determining the credit amount of commercial banks based on credit rating, the method of determining the credit amount of commercial banks based on economic capital, and so on. However, there is still a lack of comprehensive method to determine the loan limitation of commercial banks. Domestic scholars use efficiency of credit of commercial banks mainly refers to the influence of bank credit facility and customer payment proportion of the income of the project, the relationship between efficiency of loan limitation, optimization problems such as the amount of credit but there is little research on how to improve the efficiency of commercial bank loan limitation. As mentioned above, the future development direction of commercial bank loan limitation is also the direction of exploring the method to determine the loan limitation of the comprehensive commercial banks, and seeking to improve the efficiency of the commercial bank loan limitation.

\section{Acknowledgements}

This work was financially supported by National Natural Science Foundation of China (71263011).

\section{References}

[1] Dennis S, Nandy D. The Determinants of Contract Terms in Bank Revolving Credit Agreement[J]. Journal of Financial and Quantitative Analysis, 2000, 35(1):87-110.

[2] Andre P, Mathieu R, Zhang P. A Note on: Capital Adequacy and The Information Content of Term Loans and Lines of Credit[J]. Journal of Banking \& Finance, 2001, 25(2):431-444.

[3] Zambaldi F, Aranha F, Lopes H et al. Credit Granting to Small Firms: A Brazilian case[J]. Journal of Business Research, 2011, 64(3):309-315.

[4] Ariccia G D, Marquez R. Information and Bank Credit Allocation[J]. Journal of Financial Economics, 2004, 72(1):185-214.

[5] Sumit A, Souphala C. Loan Commitments and Private Firms[J]. Finance and Economics Discussion Series, 2004, (27):1-22.

[6] Chakraborty A, Hu C X. Lending Relationships in Line-of-credit and Non-line-of-credit Loans: Evidence From Collateral Use in Small Business[J]. Journal of Financial Inter-mediation, 2006, 15(1):86-107.

[7] Sufi A. Bank Lines of Credit in Corporate Finance: An Empirical Analysis[J]. Review of Financial Studies, 2009, 22(3):1057-1088.

[8] Pessarossi P, Godlewski C J, Weill L. Foreign Bank Lending and Information Asymmetries in China: Empirical Evidence from the Syndicated Loan Market[J]. Journal of Asian Economics, 2012, 23(4):423-433.

[9] Tong Z X. Coinsurance Effect and Bank Lines of Credit[J]. Journal of Banking and Finance, 2012, 36(6):1592-1603.

[10] Shen Lisheng, Wang Heng. Test on Credit-Committing Limitation Using Artificial Neural Network Model[J]. The Journal of Quantitative \&Technical Economics, 2007, 24(3):108-117. 
[11]Liu Lvke, Zhang Dingsheng. The Sensitivity of Loan Limit to the Change of Policy Interest Rate -the Experience from Australia[J]. Investment Research, 2012, 31(7):90-98.

[12] Hu Jinyan, Zhang Qiang. Loan Amount, Default Rate and Small Loan Company's Earnings: Observation of Shangdong Province[J]. Reform, 2016, (12):123-133.

[13]Li Jing. Thinking about ABC's Checking and Ratifying Model for the Highest Guild Line of Credit Authorization[J]. HAINAN FINANCE, 2003, (8):18-20.

[14]Zhou Lanzhen. The Essence of Credit Line and Option Setting[J]. Zhejiang Finance, 2003, (5):20-21.

[15]Leippoldy M. Optimal Loan Limitation Management under Different Information Regimes[J]. Journal of Banking \& Finance, 2006, 30(2):463-487.

[16]Zhou Jiangtao, ZhangYan. Research on the Formation Mechanism of Credit Concentration Risk of Commercial Banks in China[J]. Productivity Research, 2007, (17):28-29,67.

[17] Cheng Gong, Zhang Wei, Xiong Xiong. The Approach to Calculate Credit Limit on the Bases of Credit Rating[J]. Management Sciences in China, 2006, 19(2):66-71.

[18]He Zili. Ratifying Logic for Lines of Credit: An Angle of the Symbiosis Theory[J]. Finance Forum, 2007, 12(1):31-36.

[19]Taylor J. A Unified Approach to Loan Limitation Setting. (Portfolio Management)[J]. Rma Journal, 2002(July-August):56-61,72.

[20]Zhou Kai. Application of Economic Capital Management to United Credit Management of Group Customers[J]. Journal of Nanjing Agricultural University (Social Sciences Edition), 2008, $8(2): 39-43$.

[21]Liu Zhenhua, Xie Chi. A Study on the Loan Limitation of Commercial Bank Based on RAROC Model[J]. Economic Management Journal, 2012, (12):111-119.

[22]Cheng Gong, Zhang Wei. Noisy Information, Structural Model and Bank Clients' Credit Limit Management[J]. Chinese Journal of Management Science, 2008, 16(2):30-36.

[23]Zhou Minghao, Wang Xiaoying. Study on Credit Line Measurement of Unsecured Loans[J]. Financial Theory and Practice, 2010, (2):83-85.

[24] Stanhouse B, Schwarzkopf A, Ingram M. A Computational Approach to Pricing a Bank Credit Line[J]. Journal of Banking \& Finance, 2011, 35(6):1341-1351.

[25] Miao Xilin. Research on the Measurement of Short Term Credit Loan Line under Flexible Financial Management, 2014, (8):115-118.

[26] Wang Yongfeng. Research on Mutual Security Function of Housing Provident Fund Loan for Basic Living_-Methods of Determing Personal Credit Line HPF[J]. Chinese Public Administration, 2015, (2):84-87.

[27]Ren Shike, He Zhengwen, Xu Yu. Study on Bank Credit Limit Based Max-NPV Project Scheduling Problems[J]. Journal of Industrial Engineering and Engineering Management, 2009, 23(2):85-91.

[28]Ying Qianwei, Luo Danglun. Credit Lines and Investment Efficiency[J]. Journal of Financial Research, 2012, (5):151-163.

[29] Song Yibei. An Empirical Study on the Impact of Credit Line and Relationship between Government and Enterprises on Sensitivity of Investment to Cash Flow[J]. Statistics \& Decision, 2016, (4):166-169.

[30]Chen Lin, Zhou Zongfang. Research on Optimized Allocating the Unified Credit Line of Group Customer of Commercial Bank[J]. Chinese Journal of Management Science, 2015, 23(2):39-43. 